\title{
A major role for VCAM-1, but not ICAM-1, in early atherosclerosis
}

\author{
Myron I. Cybulsky, ${ }^{1}$ Kaeko Iiyama, ${ }^{1}$ Hongmei Li, ${ }^{2}$ Suning Zhu, ${ }^{1}$ Mian Chen, ${ }^{1}$ \\ Motoi Iiyama, ${ }^{1}$ Vannessa Davis, ${ }^{2}$ Jose-Carlos Gutierrez-Ramos, ${ }^{3}$ Philip W. Connelly, ${ }^{4}$ \\ and David S. Milstone ${ }^{2}$
}
${ }^{1}$ Department of Laboratory Medicine and Pathobiology, University of Toronto, Toronto General Research Institute, Toronto, Ontario, Canada
${ }^{2}$ Vascular Research Division, Departments of Pathology, Brigham and Women's Hospital and Harvard Medical School, Boston, Massachusetts, USA
${ }^{3}$ Millennium Pharmaceuticals Inc., Cambridge, Massachusetts, USA
${ }^{4}$ Departments of Laboratory Medicine and Pathobiology, Medicine, and Biochemistry, University of Toronto, St. Michael's Hospital, Toronto, Ontario, Canada

Address correspondence to: Myron I. Cybulsky, Toronto General Research Institute, 200 Elizabeth Street, CCRW 1-855, Toronto, Ontario, Canada, M5G 2C4. Phone/Fax: (416) 340-3578; E-mail: myron.cybulsky@utoronto.ca.

Received for publication November 29, 2000, and accepted in revised form March 26, 2001.

VCAM-1 and ICAM-1 are endothelial adhesion molecules of the Ig gene superfamily that may participate in atherogenesis by promoting monocyte accumulation in the arterial intima. Both are expressed in regions predisposed to atherosclerosis and at the periphery of established lesions, while ICAM-1 is also expressed more broadly. To evaluate functions of VCAM-1 in chronic disease, we disrupted its fourth Ig domain, producing the murine Vcam $1^{D 4 D}$ allele. VCAM-1 ${ }^{\mathrm{D} 4 \mathrm{D}} \mathrm{mRNA}$ and protein were reduced to $2-8 \%$ of wild-type allele $\left(V c a m 1^{+}\right)$levels but were sufficient to partially rescue the lethal phenotype of VCAM-1-null embryos. After crossing into the LDL receptor-null background, $V c a m 1^{+/+}$and $V c a m 1^{D 4 D / D 4 D}$ paired littermates were generated from heterozygous intercrosses and fed a cholesterol-enriched diet for 8 weeks. The area of early atherosclerotic lesions in the aorta, quantified by en face oil red O staining, was reduced significantly in $V c a m 1^{D 4 D / D 4 D}$ mice, although cholesterol levels, lipoprotein profiles, and numbers of circulating leukocytes were comparable to wild-type. In contrast, deficiency of ICAM-1 either alone or in combination with VCAM-1 deficiency did not alter nascent lesion formation. Therefore, although expression of both VCAM-1 and ICAM- 1 is upregulated in atherosclerotic lesions, our data indicate that VCAM-1 plays a dominant role in the initiation of atherosclerosis.

J. Clin. Invest. 107:1255-1262 (2001).

\section{Introduction}

Atherosclerotic lesion formation involves blood monocyte recruitment to the arterial intima, engulfment of lipids, and transformation into macrophage foam cells (1). Endothelial cells are activated in this process (2) and express leukocyte adhesion molecules and chemokines that contribute to atherosclerosis (3-9), in part by regulating different steps of the monocyte recruitment process. The selectins mediate initial leukocyte adhesive interactions. Chemokines then stimulate leukocytes and upregulate $\alpha 4$ and $\beta 2$ integrin binding to VCAM-1 and ICAM-1, respectively, which themselves mediate later steps (10). VCAM- 1 and ICAM-1 are closely related in structure and function. Both are cytokine-inducible Ig gene superfamily members that bind leukocyte integrins (10). In normal mice and rabbits, both VCAM-1 and ICAM-1 are expressed by aortic endothelium in regions predisposed to atherosclerosis $(11,12)$. In hypercholesterolemic animals, both are upregulated over early foam cell lesions, particularly at the periphery (11), where monocyte adhesion is maximal (13). However, VCAM-1 is unique in that its expression is largely restricted to lesions and lesion-predisposed regions, whereas ICAM-1 expression extends into uninvolved aorta and lesion-protected regions (11). This difference in expression patterns suggests different functions for VCAM-1 and ICAM-1 in lesion initiation.

Studies using ICAM-1-deficient (Icam 1-/-) mice crossed into the apoE-null $\left(A p o e^{-/-}\right)$background demonstrated a role for ICAM-1 in elaboration of "mature" atherosclerotic lesions $(5,14)$. However, analysis of VCAM-1 function in adults has not been possible because VCAM-1- and $\alpha 4$ integrin-null mice die during embryogenesis (15-17). In this study, we exploited the gene structure of VCAM-1 to generate homozygous VCAM-1 domain 4-deficient (D4D) mice $\left(V c a m 1^{D 4 D / D 4 D}\right)$. Vcam $1^{D 4 D / D 4 D}$ mice express markedly reduced levels of VCAM-1 mRNA and protein consisting of 6 Ig domains (6 Ig VCAM-1), partially circumvent the embryonic lethality of complete VCAM-1 deficiency, and enable a direct comparison of VCAM-1 and ICAM-1 in atherosclerosis. We now report a differential requirement for these two Ig 
$\mathbf{a}$

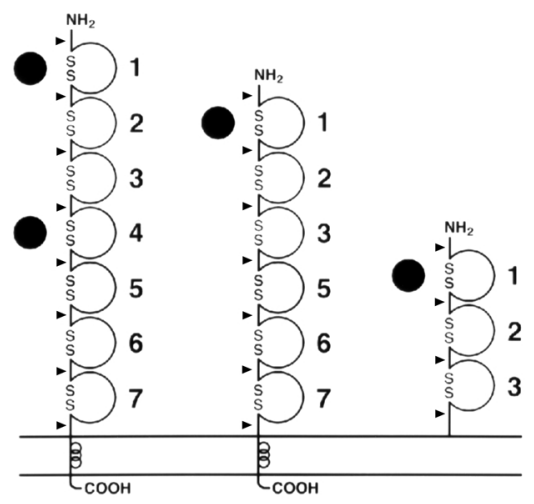

b

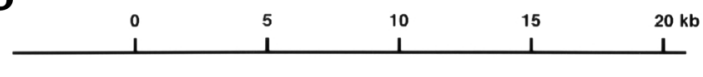

Murine VCAM1 gene
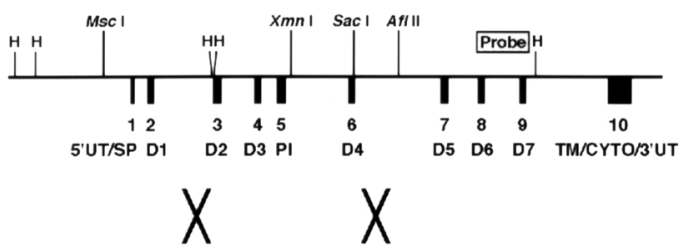

D4D VCAM-1 targeting construct

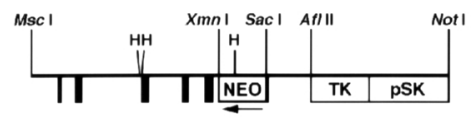

Homologous recombination at VCAM1 locus

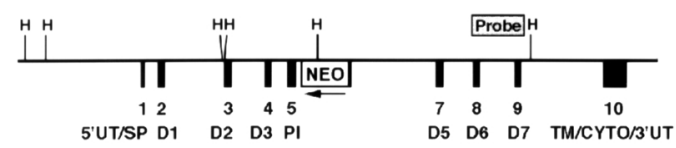

c

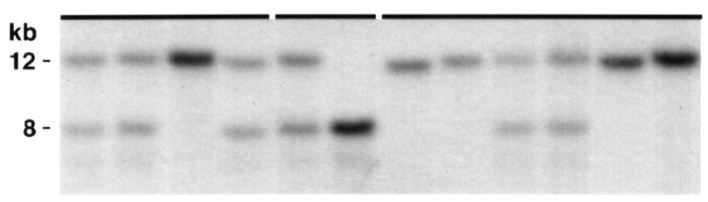

superfamily adhesion molecules in the formation of early atherosclerotic lesions throughout the entire aorta of $\mathrm{LDL}$ receptor-null $\left(\mathrm{Ldlr}^{--}\right)$mice.

\section{Methods}

Animals. Mice were group-housed and fed standard chow in a specific pathogen-free environment in accordance with all institutional and governmental guidelines.

Production of VCAM-1 D4D mice. To replace the $5^{\prime}$ portion of Vcam 1 exon 6 (encoding Ig domain 4) and the adjacent intron (Figure 1), a targeting construct included the murine phosphoglycerate kinase-1 promoter/ neomycin resistance gene (NEO) in the opposite transcriptional orientation and $7.1 \mathrm{~kb}$ of $5^{\prime}$ and $1.7 \mathrm{~kb}$ of $3^{\prime}$ homology. A mutant polyoma virus enhancer/herpes simplex virus thymidine kinase (TK) gene allowed selection against random integration. Electroporation and

\section{Figure 1}

Homologous recombination at the Vcam 1 gene locus. (a) Alternative RNA splicing produces VCAM-1 isoforms with one or two $\alpha 4$ integrin binding sites (solid circles). Loops, disulfide-linked Ig domains 1-7. Arrowheads, exon splice junctions. (b) The wild-type murine Vcam1 gene, D4D targeting construct, and homologous recombination at the Vcam 1 locus. D4 (exon 6) was disrupted by gene targeting. Black boxes, exons 1-10. D1-D7, Ig domains. PI, domain providing phosphatidylinositol linkage of $3 \mathrm{Ig}$ VCAM-1. Restriction enzyme sites and the Southern blot probe are indicated. (c) Southern blot analysis of Bam HI-digested genomic DNA from progeny of heterozygous mating. A solid line above the lanes indicates each litter. Vcam ${ }^{+}$ and $V$ cam $1^{D 4 D}$ alleles are 12 and $8 \mathrm{~kb}$, respectively.

drug selection of J1 ES cell clones were performed as described previously (15). Germline transmission was achieved with chimeric mice derived from two of six targeted ES cell lines. Both lines of mice had indistinguishable phenotypes.

Genotyping. Mice were genotyped by Southern blotting (Figure 1, b and c) or PCR. DNA was isolated from tail biopsies (18) with or without (for PCR) isopropanol precipitation. PCR products were 300 and $500 \mathrm{bp}$ for $V c a m 1^{+}$and Vcam $1^{D 4 D}$ alleles. A common forward primer (5'-ATACATTGGGTATGGTGTGATATG) was used that bound to the $3^{\prime}$ end of exon 5 [phosphatidylinositol-linked (PI) domain]. The wild-type allele reverse primer (5'-AACTTAAAATCCATGTTTTCATAGG) recognized an intron replaced by NEO in the mutant allele. The mutant allele reverse primer (5'-CAAGCAAAACCAAATTAAGGG) recognized the $3^{\prime}$ untranslated region of phosphoglycerate kinase- 1 in NEO. PCR conditions were $\left(94^{\circ} \mathrm{C} / 90 \mathrm{~s}\right.$, $\left.56^{\circ} \mathrm{C} / 60 \mathrm{~s}, 72^{\circ} \mathrm{C} / 120 \mathrm{~s}\right) \times 3,\left(94^{\circ} \mathrm{C} / 30 \mathrm{~s}, 56^{\circ} \mathrm{C} / 30 \mathrm{~s}\right.$, $\left.72^{\circ} \mathrm{C} / 60 \mathrm{~s}\right) \times 27$, and $72^{\circ} \mathrm{C} / 7 \mathrm{~min}$.

Flow cytometry. Heparinized blood was obtained from mice by cardiac puncture and $50 \mu \mathrm{l}$ was incubated with $50 \mu \mathrm{l}$ PBS containing $\mathrm{Fc}$ block (anti-mouse $\mathrm{CD} 16 / \mathrm{CD} 32$ ) and rat IgG for 20 minutes at $22^{\circ} \mathrm{C}$. Primary antibodies (rat monoclonal) were incubated for 30 minutes at $22^{\circ} \mathrm{C}$. They included biotin-conjugated anti-CD19, fluorescein-conjugated anti-CD3, fluorescein-conjugated anti-GR1, and phycoerythrin-conjugated anti-CD11b (BD PharMingen, San Diego, California, USA). Cells were washed with PBS containing $2.5 \% \mathrm{FBS}$, and incubated with streptavidin-fluorochrome if required $\left(4^{\circ} \mathrm{C}\right.$ for 30 minutes), and erythrocytes were removed by hypotonic lysis. Flow cytometry was carried out immediately after the final wash using an Epics XL-MCL flow cytometer (Coulter Corp., Miami, Florida, USA).

Northern blotting. Total RNA $(10 \mu \mathrm{g})$ isolated by ultracentrifugation through a cesium chloride gradient or mRNA $(3 \mu \mathrm{g})$ purified using oligo dT cellulose was analyzed by Northern blotting (19).

RT-PCR. RT (SuperScript kit; Life Technologies Inc., Rockville, Maryland, USA) for alternatively spliced 7 and 6 Ig VCAM-1 used a primer complementary to 
Table 1

Embryonic survival of VCAM-1-deficient mice

\begin{tabular}{|c|c|c|c|c|c|c|}
\hline \multirow[b]{2}{*}{ Strain } & \multirow[b]{2}{*}{$\begin{array}{c}\text { Vcam1 } \\
\text { genotype: }\end{array}$} & \multicolumn{3}{|c|}{ Live births } & \multirow{2}{*}{$\begin{array}{l}\text { Expected } \\
\text { births } \\
\text { D4D/D4D }\end{array}$} & \multirow{2}{*}{$\begin{array}{c}\text { Embryonic } \\
\text { survival } \\
\text { D4D/D4D }\end{array}$} \\
\hline & & $+/+$ & +/D4D & $\mathrm{D} 4 \mathrm{D} / \mathrm{D} 4 \mathrm{D}$ & & \\
\hline 129-BALB/c and $129-\mathrm{C} 57 \mathrm{BL} / 6^{\mathrm{A}}$ & & 217 & 431 & 62 & 216 & $29 \%$ \\
\hline $\mathrm{BALB} / \mathrm{c}(\mathrm{BC} \# 6$ and 7$)$ & & 155 & 245 & 33 & 133 & $25 \%$ \\
\hline $\mathrm{BALB} / \mathrm{c}(\mathrm{BC} \# 9,10$, and 11) & & 243 & 436 & 54 & 226 & $24 \%$ \\
\hline 129/SvEv & & 59 & 137 & 4 & 65 & $6 \%$ \\
\hline C57BL/ $6(\mathrm{BC} \# 4,5$, and 8) & & 67 & 93 & 3 & 53 & $6 \%$ \\
\hline
\end{tabular}

${ }^{A}$ Cam $1^{D 4 D / D 4 D}$ embryonic survival was comparable in mixed 129-BALB/c and 129-C57BL/6 strains, and the data were pooled. BC, backcross.

GATTGAATTACTGAAGG in D5. For 3 Ig VCAM-1, the RT primer was complementary to CATCATTTGCATGGGGTCA in the PI domain. PCR reactions $\left[\left(94^{\circ} \mathrm{C} / 1 \mathrm{~s}, 92^{\circ} \mathrm{C} / 29 \mathrm{~s}, 50^{\circ} \mathrm{C} / 30 \mathrm{~s}, 72^{\circ} \mathrm{C} / 60 \mathrm{~s}\right) \times 35\right]$ used a common forward primer CAATGACCTGTTCCAGCGAG from D3 and domain-specific reverse primers complementary to CCAAATCCACGCTTGTGTT (in D4), CAAGCATTCCCTGAAGATCC (spanning the junction of D3-D5), and CTTGCTCTGTGAGGAAGCTG (in the PI domain). The 382-, 217-, and 319bp products for 7, 6, and 3 Ig VCAM-1, respectively, were resolved on $1.5 \%$ agarose gels.

Immunoprecipitation and immunohistochemistry. Enzymatically isolated lung cells (20) were depleted of macrophages using anti-Fc receptor magnetic beads. For this purpose, rat monoclonal antibodies to mouse Fc $\gamma$ III and II receptors (CD16 and CD32) (PharMingen, San Diego, California, USA) were bound to M-450 magnetic beads coupled to sheep anti-rat IgG antibodies (Dynal Biotech Inc., Lake Success, New York, USA). Cells from subculture 2 were treated with media or murine TNF- $\alpha$ (20 ng/ml) for 4 hours, and cell-surface proteins were biotinylated (21). VCAM-1 and ICAM-1 proteins were quantitatively immunoprecipitated from centrifugation-cleared Triton X-100 whole cell lysates using monoclonal antibodies (rat $\mathrm{IgG}_{1}$ ) MK-2 and YN1.1, respectively, and goat anti-rat IgG-sepharose. After SDS-PAGE and transfer to polyvinylidene difluoride membranes, biotinylated cell-surface proteins were visualized using peroxidase-conjugated streptavidin and chemiluminescent emission (Amersham Pharmacia Biotech Ltd., Piscataway, New Jersey, USA) and quan- tified using a Molecular Dynamics (Sunnyvale, California, USA) densitometer. Immunoperoxidase staining of cryostat-cut sections (15) used MK-2 and YN1.1, with nonimmune rat IgG as the negative control.

Atherosclerosis studies. Vcam $1^{D 4 D / D 4 D}$ and $\mathrm{Ldlr}^{-/}$(22) mice were bred and their progeny were bred back to $\mathrm{Ldlr}^{-/}$to obtain $V c a m 1^{+/ D 4 D} \mathrm{Ldlr}^{-/-}$mice. These were intercrossed to obtain sex-matched paired littermates $\left(V c a m 1^{+/+} L d l r^{-/}\right.$and $\left.V c a m 1^{D 4 D / D 4 D} L d l r^{--}\right)$for experiments. Icam $1^{-/-}$mice (23) were backcrossed into the $\mathrm{Ldlr}^{/-}$background and intercrossed in a similar fashion. C57BL/6-129 hybrid mice were used because the viability of C57BL/6 Vcam $1^{\text {D4D/D4D }}$ embryos was very low (see Results). Also, recombination between Icam 1 and Ldlr alleles, which are within 3 centimorgans on mouse chromosome 9 (24), could not be achieved in the C57BL/ 6 background (not shown).

Paired littermates were fed a semipurified cholatefree diet (no. D12108; Research Diets Inc., New Brunswick, New Jersey, USA) containing 40\% kcal lipid, $1.25 \%$ cholesterol (25). After 8 weeks of the cholesterol-enriched diet, blood was obtained from the retroorbital plexus or by cardiac puncture and aortae were isolated. The percent of the surface area occupied by atherosclerotic lesions in the whole aorta and in specific regions (aortic arch, descending thoracic aorta, and abdominal aorta) was quantified by en face oil red $\mathrm{O}$ staining as described (25). Serum cholesterol levels and leukocyte counts (hemocytometer and differentials) were determined for each mouse. Plasma lipoprotein profiles were determined by gel filtration fast performance liquid chromatography (25) from random animals in each group.

\section{Table 2}

Total and differential leukocyte counts in VCAM-1-deficient mice and littermate controls maintained on a standard diet without elevated cholesterol

\begin{tabular}{lccccc}
\hline Genotype & Total & Monocytes & Lymphocytes & Neutrophils & Eosinophils \\
$V_{\text {cam1 }}{ }^{+/+}$ & $6.7 \pm 0.9$ & $0.3 \pm 0.1$ & $5.2 \pm 0.7$ & $1.2 \pm 0.2$ & $0.06 \pm 0.04$ \\
$V_{c a m 1^{+/ D 4 D}}$ & $6.1 \pm 1.0$ & $0.4 \pm 0.1$ & $5.0 \pm 0.7$ & $0.8 \pm 0.2$ & $0.02 \pm 0.01$ \\
$V_{c a m 1^{10 D / D 4 D}}$ & $5.8 \pm 0.9$ & $0.6 \pm 0.1^{\mathrm{A}}$ & $4.4 \pm 0.7$ & $0.8 \pm 0.3$ & $0.07 \pm 0.02$ \\
\hline
\end{tabular}

Hybrid 129-C57BL/ 6 and 129-BALB/c strain mice, age $2-4$ months, were used. Values are expressed as mean \pm SEM of cells per milliliter of blood $\times 10^{-6}$. Differential counts were based on 200 cells evaluated in each blood film. ${ }^{A} P<0.05$ versus $V$ cam $1^{+/+}$and $V$ cam $1^{+/ D 4 D}$ groups (Fisher's PLSD). 
Table 3

Flow cytometry analysis of blood leukocytes in VCAM-1-deficient mice and littermate controls maintained on a standard diet without elevated cholesterol

\begin{tabular}{|c|c|c|c|c|c|}
\hline Genotype & Total & $\begin{array}{c}\text { Monocytes } \\
\left(\mathrm{CD} 11 \mathrm{~b}^{+}, \mathrm{GR} 1^{\text {low }}\right)\end{array}$ & $\begin{array}{l}\text { T Lymphocytes } \\
\left(\mathrm{CD}^{+}, \mathrm{CD} 19^{-}\right)\end{array}$ & $\begin{array}{l}\text { B Lymphocytes } \\
\left(\mathrm{CD} 19^{+}, \mathrm{CD}^{-}\right)\end{array}$ & $\begin{array}{c}\text { Neutrophils } \\
\left(\mathrm{CD} 11 \mathrm{~b}^{+}, \mathrm{GR} 1^{\text {high }}\right)\end{array}$ \\
\hline Vcam $1^{+/+}$ & $4.2 \pm 0.7$ & $\begin{array}{c}0.4 \pm 0.04 \\
(11.4 \pm 1.2 \%)\end{array}$ & $\begin{array}{c}1.3 \pm 0.2 \\
(32.7 \pm 3.2 \%)\end{array}$ & $\begin{array}{c}1.1 \pm 0.3 \\
(25.4 \pm 3.5 \%)\end{array}$ & $\begin{array}{c}0.8 \pm 0.2 \\
(17.4 \pm 2.6 \%)\end{array}$ \\
\hline Vcam 1 $1^{D 4 D / D 4 D}$ & $6.9 \pm 0.8^{\mathrm{A}}$ & $\begin{array}{c}0.7 \pm 0.1^{\mathrm{B}} \\
(11.0 \pm 1.4 \%)\end{array}$ & $\begin{array}{c}2.0 \pm 0.1^{\mathrm{A}} \\
(30.4 \pm 1.8 \%)\end{array}$ & $\begin{array}{c}2.3 \pm 0.6^{\mathrm{B}} \\
(31.1 \pm 4.2 \%)\end{array}$ & $\begin{array}{c}1.0 \pm 0.1 \\
(16.3 \pm 1.8 \%)\end{array}$ \\
\hline
\end{tabular}

Data are expressed as mean \pm SEM of cells per $\mathrm{ml}$ of blood $\times 10^{-6}$, with percent of total cells in parentheses. BALB/c strain mice with a mean age of 8 months. ${ }^{\text {A } P}<0.005$ (paired $t$ test). ${ }^{\mathrm{B}} P<0.05$ (paired $t$ test).

Statistics. A paired Student's $t$ test (Statview 4.5; Abacus Concepts Inc., San Francisco, California, USA) was used when data were obtained from paired littermates. Data from multiple groups were analyzed by ANOVA followed by Fisher's protected least significant difference (PLSD) test to calculate pairwise comparisons.

\section{Results}

Of three distinct VCAM-1 polypeptides (Figure 1a) derived by alternative splicing $(26,27)$, the predominant form in mice and humans contains seven Ig domains and two $\alpha 4$ integrin-binding sites, in D1 and D4 (28, 29). By disrupting D4 we generated mice that expressed only alternatively spliced VCAM-1 with one ligandbinding site. Embryonic survival of Vcam $1^{D 4 D / D 4 D}$ mice was reduced and strain-dependent: $29 \%$ in hybrid 129 $\mathrm{C} 57 \mathrm{BL} / 6$ and $129-\mathrm{BALB} / \mathrm{c}, 24 \%$ in $\mathrm{BALB} / \mathrm{c}, 6 \%$ in $\mathrm{C} 57 \mathrm{BL} / 6$, and $6 \%$ in 129 (Table 1). At 9.5 and 12.5 days gestation, more than $50 \%$ of $V c a m 1^{D 4 D / D 4 D}$ embryos displayed chorioallantoic fusion defects and embryonic demise similar to that found in Vcam1 $1^{-1-}$ mice (15).

Viable Vcam $1^{D 4 D / D 4 D}$ mice were healthy and fertile and had normal organs and body weight. This is interesting in light of the potential roles proposed for VCAM-1 and its ligand $\alpha 4 \beta 1$ integrin in embryonic development, including maintenance of pericardial integrity (17), myogenesis (30), and hematopoiesis (31-33). The number of blood leukocytes obtained at age 2-4 months from $129-\mathrm{C} 57 \mathrm{BL} / 6$ and $129-\mathrm{BALB} / \mathrm{c}$ $V c a m 1^{D 4 D / D 4 D}$ mice was comparable to $V c a m 1^{+/ D 4 D}$ and$V$ cam $1^{+/+}$littermates, but the differential revealed a small yet significant elevation in monocytes (Table 2). In somewhat older animals (average age 8 months) backcrossed over six times into the BALB/c background, blood leukocytes were elevated 1.6-fold in Vcam $1^{D 4 D / D 4 D}$ mice (Table 3 ). Flow cytometry showed that the percent of different leukocyte types was comparable, but absolute numbers of monocytes, T lymphocytes, and B lymphocytes were elevated, whereas the number of neutrophils was not significantly different (Table 3). In very old BALB/c-strain Vcam $1^{D 4 D / D 4 D}$ mice (average age 15 months, range 8-19 months), blood leukocytes were also elevated by 1.4 -fold $\left(9.7 \pm 0.7 \times 10^{6}\right.$ versus $6.9 \pm 0.7 \times 10^{6}$ cells $/ \mathrm{ml}, P<0.05, n=6$ ) due to elevated mononuclear leukocytes. These data suggest that strain rather than age differences cooperate with adhesion molecule deficiency to account for elevated circulating mononuclear leukocytes in BALB/c Vcam $1^{\text {D4D/D4D }}$ mice. Previously, in vitro studies using Dexter-type long-term bone marrow cultures derived from $V c a m 1^{D 4 D / D 4 D}, V c a m 1^{+/ D 4 D}$, and $V c a m 1^{+/+}$littermates demonstrated comparable stromal cell composition and myeloid differentiation, as well as similar flow cytometry profiles of bone marrow, blood, and lymphoid organs (34). VCAM-1 is expressed in lymphoid follicular dendritic cells and may participate in the

\section{Table 4}

Age, body weight, total serum cholesterol, and leukocyte counts in adhesion molecule-deficient and control mice in the $L d l r^{\prime-}$ background determined after feeding a cholesterol-enriched diet for 8 weeks

\begin{tabular}{|c|c|c|c|c|c|c|c|c|c|c|}
\hline $\begin{array}{l}\text { Genotype } \\
\text { (all } L d l r^{-1-} \text { ) }\end{array}$ & $\begin{array}{c}\text { Aortae } \\
\text { analyzed }\end{array}$ & $\begin{array}{l}\text { Sex } \\
(M / F)\end{array}$ & $\begin{array}{c}\text { Age } \\
\text { (weeks) }\end{array}$ & $\begin{array}{c}\text { Body } \\
\text { weight }(\mathrm{g})\end{array}$ & $\begin{array}{c}\text { Cholesterol } \\
(\mathrm{mmol} / \mathrm{l})\end{array}$ & Total & Mono. & $\begin{array}{c}\text { ukocyte co } \\
\text { Lym. }\end{array}$ & Neut. & Eos. \\
\hline Vcam $1^{+/+}$ & 12 & $4 / 8$ & $17 \pm 2$ & $24.3 \pm 2.5$ & $15.7 \pm 3.8$ & $4.8 \pm 0.8$ & $0.5 \pm 0.1$ & $3.7 \pm 0.7$ & $0.6 \pm 0.2$ & $0.07 \pm 0.03$ \\
\hline Vcam 1 D4D/D4D & 12 & $3 / 9$ & $17 \pm 2$ & $22.0 \pm 1.9$ & $23.6 \pm 4.3$ & $4.5 \pm 1.1$ & $0.4 \pm 0.1$ & $3.5 \pm 0.8$ & $0.5 \pm 0.1$ & $0.09 \pm 0.04$ \\
\hline $\operatorname{lcam} 1^{+/+}$ & 8 & $4 / 4$ & $31 \pm 2$ & $31.0 \pm 2.6$ & $25.8 \pm 3.2$ & $2.6 \pm 0.6$ & $0.3 \pm 0.1$ & $1.8 \pm 0.4$ & $0.4 \pm 0.1$ & $0.02 \pm 0.01$ \\
\hline Icam $1^{-/-}$ & 8 & $4 / 4$ & $31 \pm 2$ & $32.5 \pm 2.5$ & $27.4 \pm 1.3$ & $4.8 \pm 1.0$ & $0.3 \pm 0.1$ & $3.1 \pm 0.8$ & $1.3 \pm 0.2^{\mathrm{A}}$ & $0.07 \pm 0.03$ \\
\hline Vcam $1^{+/+} / \mathrm{cam} 1^{+/+}$ & 11 & $3 / 8$ & $15 \pm 1$ & $21.4 \pm 1.5$ & $17.1 \pm 3.9$ & $4.1 \pm 1.0$ & $0.5 \pm 0.2$ & $2.9 \pm 0.7$ & $0.6 \pm 0.1$ & $0.10 \pm 0.03$ \\
\hline V cam $1^{+/+} / \mathrm{cam} 1^{-/-}$ & 12 & $3 / 9$ & $15 \pm 1$ & $21.6 \pm 0.6$ & $16.8 \pm 2.5$ & $4.8 \pm 0.7$ & $0.5 \pm 0.1$ & $3.1 \pm 0.4$ & $1.1 \pm 0.2^{\mathrm{B}}$ & $0.04 \pm 0.02$ \\
\hline 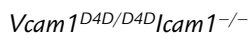 & -12 & $3 / 9$ & $15 \pm 1$ & $20.0 \pm 0.7$ & $8.2 \pm 1.6^{\mathrm{B}}$ & $10.9 \pm 2.0^{\mathrm{B}}$ & $1.5 \pm 0.5^{\mathrm{B}}$ & $7.0 \pm 1.2^{\mathrm{B}}$ & $2.1 \pm 0.4^{B}$ & $0.19 \pm 0.07$ \\
\hline
\end{tabular}

Values are expressed as mean \pm SEM. 129-C57BL/ 6 strain mice were used. Blood samples were obtained after 8 weeks of cholesterol diet feeding, and immediately prior to perfusion-fixation of aortae. The age and body weight of mice at this time point are indicated. Leukocytes are expressed as cells per milliliter of blood $\left(\times 10^{-6}\right)$. Differentials were based on 200 cells evaluated in each blood film. ${ }^{A} P<0.005$ (paired $t$ test). ${ }^{B} P<0.05$ (Fisher's PLSD). Mono., monocytes; Lym., lymphocytes; Neut., neutrophils; Eos., eosinophils. 
organization of lymphoid tissue (35). However, the spleen, lymph nodes, and Peyer's patches displayed comparable weight (e.g., spleen: $0.14 \pm 0.07 \mathrm{~g}$ $V c a m 1^{D 4 D / D 4 D}$ vs. $\left.0.11 \pm 0.01 \mathrm{~g} \mathrm{Vcam}^{+/+}\right)$and numbers of $\mathrm{T}, \mathrm{B}$, and myeloid cells, determined by flow cytometry (not shown).

Constitutive and inducible VCAM-1 mRNA and protein expression in $V c a m 1^{D 4 D / D 4 D}$ mice was reduced to less than $10 \%$ of wild-type, whereas ICAM-1 was unperturbed (Figure 2). The predominant mRNA transcript corresponded to 6 Ig VCAM-1 and was only $2-8 \%$ as abundant as 7 Ig VCAM-1 in wild-type littermates (Figure 2a). Northern blots and RT-PCR (Figure 2b) did not detect 7 Ig VCAM-1 in Vcam $1^{D 4 D / D 4 D}$ mice. Immunoprecipitation revealed reduced (7-8\% band density) TNF- $\alpha$-inducible expression of 6 Ig VCAM-1 (80-85 $\mathrm{kDa}$ ) in $V c a m 1^{D 4 D / D 4 D}$ cultured lung cells (Figure 2c). Immunostaining of $V c a m 1^{D 4 D / D 4 D}$ tissues 4 hours after endotoxin injection $(50 \mu \mathrm{g}$ intraperitoneally) showed markedly reduced VCAM-1 and normal ICAM-1 expression. Weak VCAM-1 staining was detected in endothelium of some blood vessels (not shown).

Atherosclerosis studies were carried out after breeding 129-C57BL/6 VCAM-1- and ICAM-1-deficient mice into the $\mathrm{Ldlr}^{-/}$background and feeding a cholesterol-enriched diet for 8 weeks. In all genotypes, the body weight of mice was comparable, as was the extent of hypercholesterolemia except for mice with combined VCAM-1 and ICAM-1 deficiency (Table 4). The plasma lipoprotein profile, which we reported previously (25), was similar in all genotypes (not shown). Circulating leukocytes were comparable in hypercholesterolemic $V c a m 1^{D 4 D / D 4 D}$ and $V c a m 1^{+/+}$controls (Table 4), similar to normocholesterolemic mice that were $129-\mathrm{C} 57 \mathrm{BL} / 6$ or 129-BALB/c strain hybrids (Table 2), and distinct from mice in the BALB/c background (Table 3 ), which was not used for atherosclerosis studies. The numbers of circulating monocytes, lymphocytes, and eosinophils were also comparable in mice with ICAM-1 deficiency,

\section{Figure 2}

VCAM-1 expression in Vcam $1^{D 4 D / D 4 D}$ mice. (a) Northern blot analysis of VCAM-1, ICAM-1, and $\beta$-actin expression using total or oligo dT-enriched

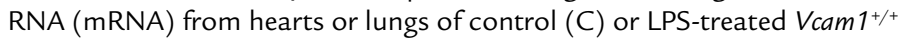
$(+/+), V_{c a m} 1^{+/ D 4 D}(+/ D 4 D)$, and Vcam 1D4D/D4D (D4D/D4D) mice. Bars on the right indicate $18 \mathrm{~S}$ ribosomal RNA migration. Transcripts corresponding to the 7 (asterisks) and 3 (filled diamonds) Ig VCAM-1 were found in $V \mathrm{cam} 1^{+/+}$and $V \mathrm{cam} 1^{+/ D 4 D}$ mice, whereas expression of 6 (arrowheads) and possibly 4 (open circle) Ig domain forms was found in VCAM-1D4D/D4D mice. (b) RT-PCR analysis of 7, 6, and 3 Ig VCAM-1 (7D, 6D, 3D) mRNA in lungs of LPS-treated mice. In Vcam $1^{D 4 D / D 4 D}$ mice, domain-specific primers did not detect D4 found in 7 Ig VCAM-1. (c) Immunoprecipitation of cell surface VCAM-1 and ICAM-1 from Vcam $1^{+/+}$and $V c a m 1^{D 4 D / D 4 D}$ biotin-labeled cultured lung endothelial cells. TNF induced expression of $90-$ to $95-\mathrm{kDa}$ (asterisk) and 36- to 40-kDa (filled diamond) proteins, corresponding to 7 and 3 Ig VCAM-1, in $\mathrm{Vcam}^{+/+}$cells, and 80 - to $85-\mathrm{kDa}$ (arrowhead) and possibly 50 - to $60-\mathrm{kDa}$ (open circle) proteins, corresponding to 6 and $4 \lg$ VCAM- 1 in VCAM-1D4D/D4D cells. No 7 Ig VCAM-1 was detected in VCAM-1D4D/D4D cells. TNF-induced ICAM- 1 expression was comparable. but neutrophils were elevated (Table 4), consistent with previous reports $(23,36)$. Circulating monocytes, lymphocytes, and neutrophils were elevated in mice with combined VCAM-1 and ICAM-1 deficiency (Table 4). Atherosclerotic lesions in aortae of $\mathrm{Ldlr}^{-/-}$mice fed cholesterol-enriched diet for 8 weeks consisted of acrophage foam cell-rich fatty streaks. Immunosing of lesions in the aortic arches of 政 estected oil red $\mathrm{O}$ staining demonstrated that these lesions were most prevalent in the lesser curvature of the ascending aorta and arch. The distribution of lesions
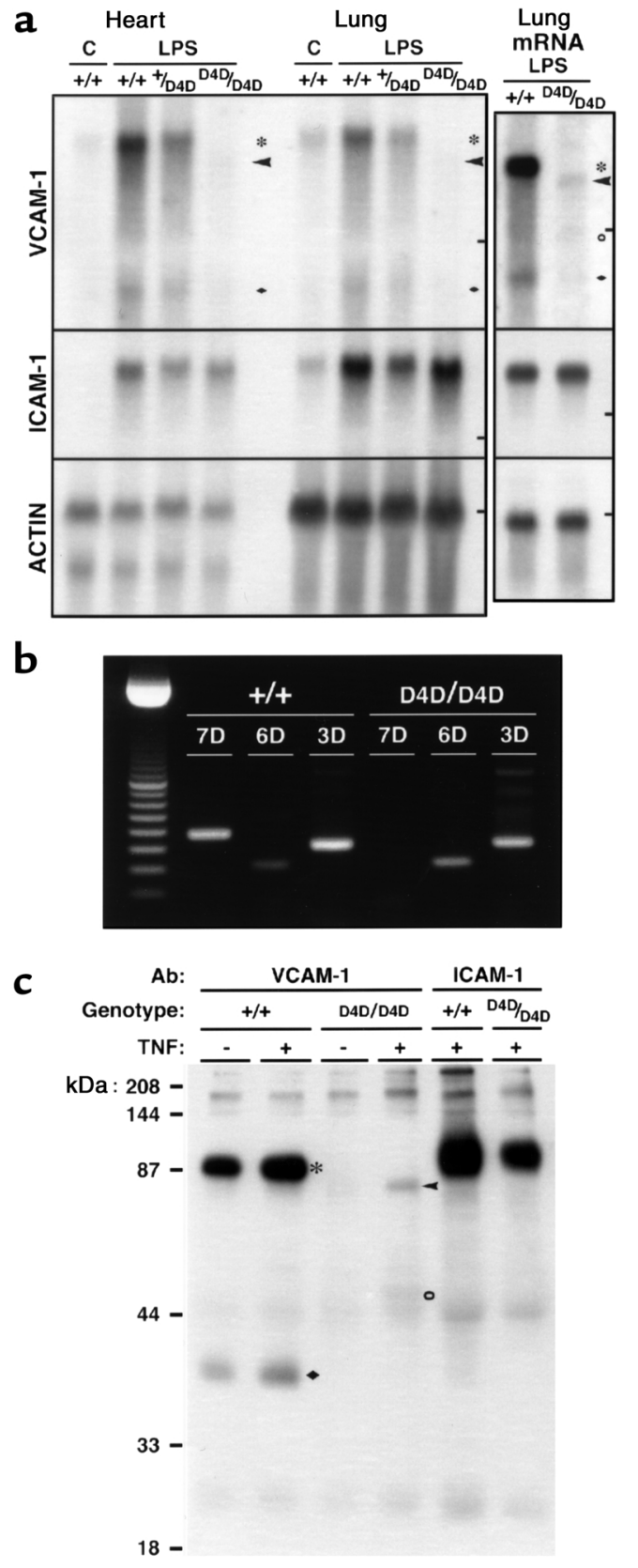

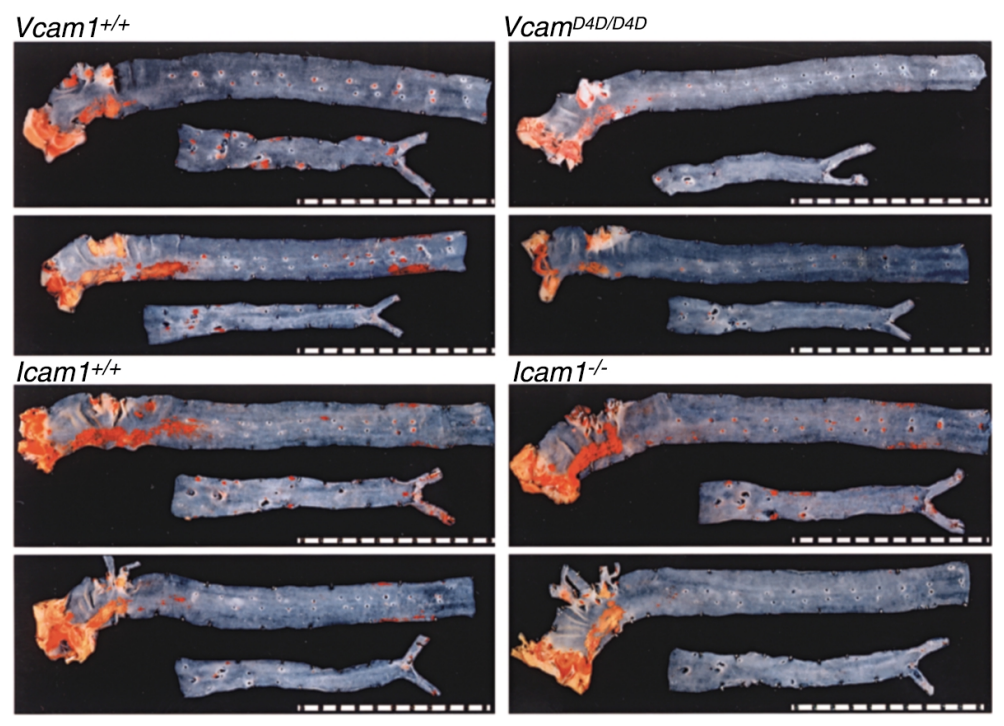

\section{Figure 3}

VCAM-1 deficiency reduces the extent but does not alter the topography of atherosclerotic lesions. Representative oil red O-stained aortae from paired littermates demonstrate high lesion prevalence in the lesser curvature of the ascending aorta and arch. Scale bars are at 1-mm intervals.

in mice deficient in adhesion molecules was identical (Figure 3). Data from male and female mice were combined, because differences in lesion area were not found between sexes. The surface area occupied by lesions was reduced by $40 \%$ in $V c a m 1^{D 4 D / D 4 D} \mathrm{Ldlr} /-$ mice (Figure 4). This effect was prominent in the arch, but differences were not significant in the descending thoracic and abdominal aorta because the extent of lesions in this region was relatively low ( $<2 \%$ of surface area) and variability was high. Interanimal variability within each genotype may have been partly the result of genetic background heterogeneity but was unavoidable (see Methods).

The area of lesions was not reduced in aortae or any aortic region of Icam $1^{-/} \mathrm{Ldlr} /-$ mice compared with Icam $1^{+/} \mathrm{Ldlr}^{-/}$sex-matched littermates (Figure $4 \mathrm{~b}$ ) and was similar to that of $\mathrm{Vcam}^{+/+}$mice in Figure 4a, supporting the reproducibility of the model. The effect of combined VCAM-1 and ICAM-1 deficiency was assessed by crossing Vcam $1^{\text {D4D/D4D }} \mathrm{Ldlr}^{-/}$with Icam $1^{-/-} \mathrm{Ldlr}{ }^{-/}$mice and intercrossing the progeny to produce Vcam1 $1^{\text {DAD/D4D }}$ and $\mathrm{Vcam1}^{+/+}$litter-mates in the Icam $1^{-/} \mathrm{Ldlr}^{-/}$background. $V \mathrm{Cam} 1^{+/+} \mathrm{Icam}^{+/+} \mathrm{Ldlr}^{-/}$mice derived from this breeding served as a control group but were not littermates. The whole aorta and arch lesion area in $V c a m 1^{D 4 D / D 4 D} I c a m 1^{-/-} L d l r^{-/}$mice was reduced by $31 \%$ and $45 \%$, respectively, versus $\mathrm{Vcam} \mathrm{I}^{+/+} \mathrm{Icam} \mathrm{1}^{-/-} \mathrm{Ldlr}^{-/}$littermates, and by $48 \%$ and $38 \%$, respectively, versus the

\section{Figure 4}

VCAM-1 but not ICAM-1 deficiency reduces atherosclerotic lesion area in $\mathrm{Ldll}^{-1-}$ mice. Data from the whole aorta and from different regions are shown. Each data point (left) represents a value from a single mouse, and the mean \pm SEM of the group is on the right.
$\mathrm{Vcam}^{+/+} I \mathrm{cam} 1^{+/+} \mathrm{Ldlr}^{-/}$group (Figure 4c). These reductions in lesion area were comparable to those found with VCAM-1 deficiency alone (Figure 4a). These data should be interpreted with caution, because significant differences in total serum cholesterol and circulating leukocytes were found in $V c a m 1^{D 4 D / D 4 D} I c a m 1^{-/-} \mathrm{Ldlr}^{-/}$mice (Table 4). ICAM-1 deficiency did not alter atherosclerotic lesion area in any of our experiments (Figure 4, b and c).
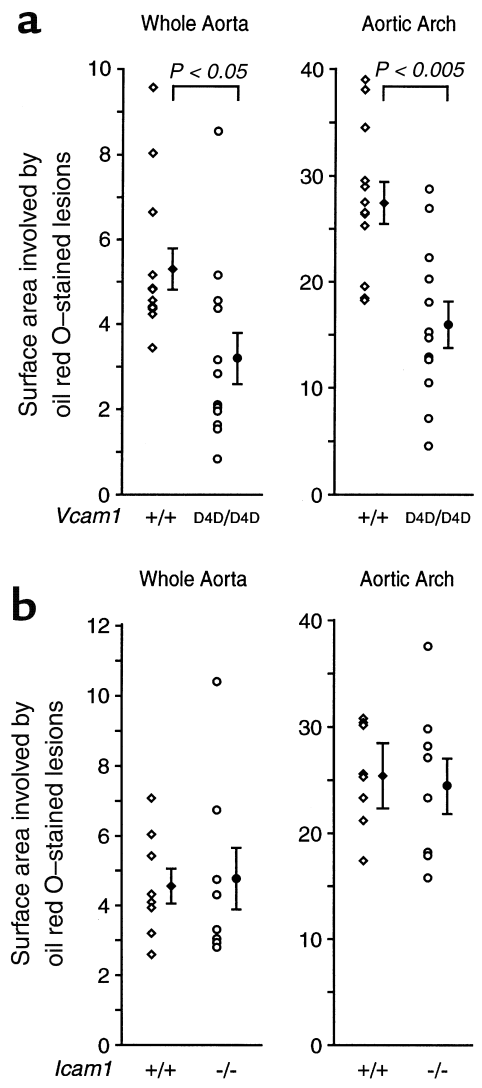
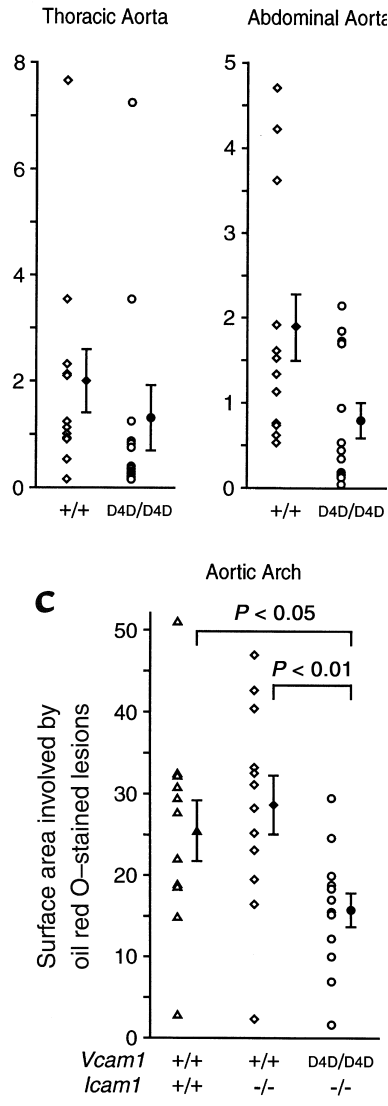


\section{Discussion}

We developed mice that express 6 Ig VCAM-1 (with one ligand-binding site) at levels less than $10 \%$ of wild-type, and used them to directly compare the roles of VCAM1 and ICAM- 1 in atherosclerosis. Our data indicate that deficiency of VCAM-1 significantly diminishes early foam cell lesion formation throughout the aorta of $\mathrm{Ldlr}^{-/}$mice, and suggest that VCAM-1 has a major role in the initiation of atherosclerosis. The expression of VCAM-1 in our model was markedly reduced but not abolished, and it is possible that complete deficiency of VCAM-1 may have caused even more dramatic effects. Our data are consistent with a recent study by Dansky et al. (37). These investigators bred our VCAM-1 mutant mice into the $\mathrm{Apoe}^{-/-}$background and demonstrated marked reductions in aortic root lesions, which were critically dependent on $V c a m 1^{D 4 D}$ gene dosage.

ICAM-1, an adhesion molecule with similar structure, function, and expression patterns, may compensate for VCAM-1 or cooperate with it in various inflammatory conditions, as is the case with P- and E-selectin (4). However, this was not observed in our experiments. Instead, we found that ICAM-1 deficiency did not influence early foam cell lesion formation either alone or when combined with VCAM-1 deficiency. ICAM-1 deficiency reduced aortic lesion area in $A p o e^{-/-}$mice $(5,14)$, although another study did not observe an effect (38). These studies used mice bearing a mutation in exon 5 (36), which encodes the nonfunctional fourth Ig domain of ICAM-1. In contrast, we used mice bearing a mutation in exon 4 (23), which encodes the third Ig domain of ICAM-1 containing the Mac-1 binding site. Both exon 5 and exon 4 ICAM-1 mutants are not null alleles but express markedly reduced levels of alternatively spliced mRNA such that the corresponding variant polypeptides are present at low levels on the cell surface, and at different levels in the circulation (39-41). Relative to wild-type mice, basal levels and the TNF- $\alpha$ stimulation ratio of circulating variant ICAM-1 polypeptides are reduced twofold and sevenfold, respectively, in the exon 5 mutant mice $(40,41)$, whereas these parameters are not altered by the exon 4 mutation (41). It is thus possible that the differences in circulating ICAM- 1 between mice bearing the exon 5 and mice bearing the exon 4 mutations may influence atherogenesis and account for the absence of a significant ICAM-1 effect in our study. Alternatively, this might reflect less dependence on adhesion molecules in $\mathrm{Ldll}^{-/}$- mice compared with $\mathrm{Apoe}^{-/-}$mice, as was suggested by experiments examining P-selectin deficiency $(3,5,6)$.

In $\mathrm{Apoe}^{-/-}$mice, hypercholesterolemia occurs spontaneously and lesions form shortly after birth, whereas in $\mathrm{Ldl}^{-/}$- mice these processes are initiated by feeding a cholesterol-enriched diet. This diet is usually delayed, as in our study, until the animals are mature, such that the elapsed time since lesion initiation is usually shorter in $\mathrm{Ldlr}^{-/-}$mice compared with Apoe-/- mice of the same age. A preferential role for ICAM-1 in lesion progression as compared with lesion initiation may thus explain the lack of effect of ICAM-1 deficiency on lesions in $\mathrm{Ldlr}^{-/}$ mice in our current study. This hypothesis is supported by our preliminary experiments, in which we extended the duration of cholesterol feeding to 20 weeks and found that ICAM-1 deficiency reduced aortic lesion area by $25 \%$ in Icam $1^{-/-} \mathrm{Ldlr}^{-/}$mice (not shown). Similar inhibition of lesion progression, but not initiation, was observed in CD154-deficient (CD40 ligand-deficient)

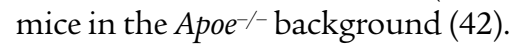

Many leukocyte adhesion molecules may contribute to atherosclerosis, yet the relatively large reductions of early foam cell lesions that we observed in $V c a m 1^{D 4 D / D 4 D} L d l r^{-/}$mice and that Dansky and colleagues found in $V c a m 1^{D 4 D / D 4 D} A p o e^{-/-}$mice (37) suggest a major role for VCAM-1 in the initiation of this disease process. This likely reflects an important function for VCAM-1 in recruitment of monocytes to the arterial intima. Reduced monocyte adhesion found in the aortic arch of Vcam $1^{D 4 D / D 4 D} A p o e^{-/-}$mice (37) is consistent with this mechanism, as are observations that antibody blockade of VCAM-1 significantly reduced monocyte rolling and adhesion in perfused carotid arteries isolated from $\mathrm{Apoe}^{-/-}$mice $(43,44)$. Interaction with VCAM-1 may modulate subsequent monocyte/ macrophage activation, and the role of VCAM- 1 in activation, proliferation, and apoptosis of intimal monocytes/macrophages, as well as in lesion progression and expansion, remains to be determined.

\section{Acknowledgments}

We thank Jeanne-Marie Kiely for assistance with immunoprecipitations. This research was supported by Heart and Stroke Foundation of Ontario grant T-3588 (to M.I. Cybulsky), Canadian Institutes of Health Research grant MT-14151 (to M.I. Cybulsky), and NIH grants HL-5409 and HL-30628 (to D.S. Milstone). M.I. Cybulsky was an Established Investigator of the American Heart Association and D.S. Milstone was a Clinician Scientist of the American Heart Association.

\footnotetext{
1. Ross, R. 1999. Atherosclerosis: an inflammatory disease. N. Engl. J. Med. 340:115-126.

2. Cybulsky, M.I., and Gimbrone, M.A., Jr. 1991. Endothelial expression of a mononuclear leukocyte adhesion molecule during atherogenesis. Science. 251:788-791.

3. Johnson, R.C., et al. 1997. Absence of P-selectin delays fatty streak formation in mice. J. Clin. Invest. 99:1037-1043.

4. Dong, Z.M., et al. 1998. The combined role of P- and E-selectins in atherosclerosis. J. Clin. Invest. 102:145-152.

5. Collins, R.G., et al. 2000. P-selectin or intercellular adhesion molecule (ICAM)-1 deficiency substantially protects against atherosclerosis in apolipoprotein E-deficient mice. J. Exp. Med. 191:189-194.

6. Dong, Z.M., Brown, A.A., and Wagner, D.D. 2000. Prominent role of Pselectin in the development of advanced atherosclerosis in ApoE-deficient mice. Circulation. 101:2290-2295.

7. Boisvert, W.A., Santiago, R., Curtiss, L.K., and Terkeltaub, R.A. 1998. A leukocyte homologue of the IL- 8 receptor CXCR- 2 mediates the accumulation of macrophages in atherosclerotic lesions of LDL receptordeficient mice. J. Clin. Invest. 101:353-363.

8. Boring, L., Gosling, J., Cleary, M., and Charo, I.F. 1998. Decreased lesion formation in CCR2-/- mice reveals a role for chemokines in the initiation of atherosclerosis. Nature. 394:894-897.

9. Gu, L., et al. 1998. Absence of monocyte chemoattractant protein-1 reduces atherosclerosis in low density lipoprotein receptor-deficient mice. Mol. Cell. 2:275-281.

10. Springer, T.A. 1994. Traffic signals for lymphocyte recirculation and
} 
leukocyte emigration: the multistep paradigm. Cell. 76:301-314.

11. Iiyama, K., et al. 1999. Patterns of vascular cell adhesion molecule-1 and intercellular adhesion molecule- 1 expression in rabbit and mouse atherosclerotic lesions and at sites predisposed to lesion formation. Circ. Res. 85:199-207.

12. Nakashima, Y., Raines, E.W., Plump, A.S., Breslow, J.L., and Ross, R. 1998 Upregulation of VCAM-1 and ICAM-1 at atherosclerosis-prone sites on the endothelium in the ApoE-deficient mouse. Arterioscler. Thromb. Vasc. Biol. 18:842-851.

13. Walker, L.N., Reidy, M.A., and Bowyer, D.E. 1986. Morphology and cell kinetics of fatty streak lesion formation in the hypercholesterolemic rabbit. Am. J. Pathol. 125:450-459.

14. Bourdillon, M.C., et al. 2000. ICAM-1 deficiency reduces atherosclerotic lesions in double-knockout mice (ApoE ${ }^{-/} / \mathrm{ICAM}^{-1 /-}$ ) fed a fat or a chow diet. Arterioscler. Thromb. Vasc. Biol. 20:2630-2635.

15. Gurtner, G.C., et al. 1995. Targeted disruption of the murine VCAM1 gene: essential role of VCAM-1 in chorioallantoic fusion and placentation. Genes Dev. 9:1-14.

16. Kwee, L., et al. 1995. Defective development of the embryonic and extraembryonic circulatory systems in vascular cell adhesion molecule (VCAM-1) deficient mice. Development. 121:489-503.

17. Yang, J.T., Rayburn, H., and Hynes, R.O. 1995. Cell adhesion events mediated by alpha 4 integrins are essential in placental and cardiac development. Development. 121:549-560.

18. Laird, P.W., et al. 1991. Simplified mammalian DNA isolation procedure. Nucleic Acids Res. 19:4293.

19. Virca, G.D., Northemann, W., Shiels, B.R., Widera, G., and Broome, S. 1990. Simplified northern blot hybridization using $5 \%$ sodium dodecyl sulfate. Biotechniques. 8:370-371.

20. Gerritsen, M.E., et al. 1995. Activation-dependent isolation and culture of murine pulmonary microvascular endothelium. Microcirculation. 2:151-163.

21. Lantz, L.M., and Holmes, K.L. 1995. Improved nonradioactive cell surface labeling technique for immunoprecipitation. Biotechniques. 18:56, 58, 60

22. Ishibashi, S., et al. 1993. Hypercholesterolemia in low density lipoprotein receptor knockout mice and its reversal by adenovirus-mediated gene delivery. J. Clin. Invest. 92:883-893.

23. Xu, H., et al. 1994. Leukocytosis and resistance to septic shock in intercellular adhesion molecule 1-deficient mice. J. Exp. Med. 180:95-109.

24. Imai, K., and Kingsley, D.M. 1994. Mouse chromosome 9. Mamm. Genome. 5:S139-S153.

25. Lichtman, A.H., et al. 1999. Hyperlipidemia and atherosclerotic lesion development in LDL receptor deficient mice fed defined semi-purified diets with and without cholate. Arterioscler. Thromb. Vasc. Biol. 19:1938-1944.

26. Cybulsky, M.I., Allan-Motamed, M., and Collins, T. 1993. Structure of the murine VCAM1 gene. Genomics. 18:387-391.

27. Cybulsky, M.I., et al. 1991. Gene structure, chromosomal location, and basis for alternative mRNA splicing of the human VCAM1 gene. Proc. Natl. Acad. Sci. USA. 88:7859-7863.
28. Osborn, L., et al. 1994. Arrangement of domains, and amino acid residues required for binding of vascular cell adhesion molecule- 1 to its counter-receptor VLA-4 (alpha 4 beta 1). J. Cell Biol. 124:601-608.

29. Vonderheide, R.H., Tedder, T.F., Springer, T.A., and Staunton, D.E. 1994. Residues within a conserved amino acid motif of domains 1 and 4 of VCAM-1 are required for binding to VLA-4. J. Cell Biol. 125:215-222.

30. Rosen, G.D., et al. 1992. Roles for the integrin VLA-4 and its counter receptor VCAM-1 in myogenesis. Cell. 69:1107-1119.

31. Miyake, K., et al. 1991. A VCAM-like adhesion molecule on murine bone marrow stromal cells mediates binding of lymphocyte precursors in culture. J. Cell Biol. 114:557-565.

32. Miyake, K., Weissman, I.L., Greenberger, J.S., and Kincade, P.W. 1991. Evidence for a role of the integrin VLA-4 in lympho-hemopoiesis. J. Exp. Med. 173:599-607.

33. Simmons, P.J., et al. 1992. Vascular cell adhesion molecule-1 expressed by bone marrow stromal cells mediates the binding of hematopoietic progenitor cells. Blood. 80:388-395.

34. Friedrich, C., Cybulsky, M.I., and Gutierrez-Ramos, J.C. 1996. Vascular cell adhesion molecule- 1 expression by hematopoiesis-supporting stromal cells is not essential for lymphoid or myeloid differentiation in vivo or in vitro. Eur. J. Immunol. 26:2773-2780.

35. Freedman, A.S., et al. 1990. Adhesion of human B cells to germinal centers in vitro involves VLA-4 and INCAM-110. Science. 249:1030-1033.

36. Sligh, J.E., Jr., et al. 1993. Inflammatory and immune responses are impaired in mice deficient in intercellular adhesion molecule 1. Proc. Natl. Acad. Sci. USA. 90:8529-8533.

37. Dansky, H.M., Barlow, C.B., Cybulsky, M.I., and Smith, J.D. 2000. Decreased endothelial VCAM-1 expression reduces monocyte adherence and atherosclerosis in apolipoprotein E-deficient mice. Circulation. 102(Suppl.):A43660. (Abstr.)

38. Smith, J.D. 1998. Mouse models of atherosclerosis. Lab. Anim. Sci. 48:573-579.

39. King, P.D., et al. 1995. Novel isoforms of murine intercellular adhesion molecule-1 generated by alternative RNA splicing. J. Immunol. 154:6080-6093.

40. Komatsu, S., Flores, S., Gerritsen, M.E., Anderson, D.C., and Granger, D.N. 1997. Differential up-regulation of circulating soluble and endothelial cell intercellular adhesion molecule-1 in mice. Am. J. Pathol. 151:205-214

41. van Den Engel, N.K., Heidenthal, E., Vinke, A., Kolb, H., and Martin, S. 2000. Circulating forms of intercellular adhesion molecule (ICAM)- 1 in mice lacking membranous ICAM-1. Blood. 95:1350-1355.

42. Lutgens, E., et al. 1999. Requirement for CD154 in the progression of atherosclerosis. Nat. Med. 5:1313-1316.

43. Ramos, C.L., et al. 1999. Direct demonstration of P-selectin- and VCAM1-dependent mononuclear cell rolling in early atherosclerotic lesions of apolipoprotein E-deficient mice. Circ. Res. 84:1237-1244.

44. Huo, Y., Hafezi-Moghadam, A., and Ley, K. 2000. Role of vascular cell adhesion molecule- 1 and fibronectin connecting segment- 1 in monocyte rolling and adhesion on early atherosclerotic lesions. Circ. Res. 87:153-159. 